Features of personal income inequality before and during the crisis: an analysis of Italian regions

[Authors] 


\title{
Features of personal income inequality before and during the crisis: an analysis of Italian regions
}

\author{
This paper gives extensive evidence of disposable income inequality inside regions of \\ Italy and its associated population features. It explores whether the Great Recession \\ changed income inequality within or between regions. Inequality appears largely to be a \\ within-region problem, particularly in the South, and the crisis exacerbated this \\ phenomenon. Middle class women, migrants and large households in middle/bottom \\ classes, and bottom class mothers worsened their income status with the crisis. \\ Education was an important absorber for middle class individuals while married status \\ and employment protected bottom class individuals. Yet, large heterogeneity exists \\ across regions.
}

Keywords: income inequality, regions, economic crisis, quantile regression analysis

Subject classification codes: D31, F22, O15, R23

\section{Introduction}

The burst of last economic crisis and its persistent effects on the Italian economy is a matter of concern not only for we observe a significant change in per capita income growth and levels, but also because it might enlarge significantly the already high dispersion among population categories and regional partition. There is a wide literature exploring the origins of Italian regional disparities, ${ }^{1}$ especially the North-South divide - from historical background and cyclical dynamics (Canale \& Napolitano, 2015), inequality of opportunities (Checchi \& Peragine, 2010), different endowment of human capital (Gagliardi \& Percoco, 2011), economic development and growth (Iyke \& Ho, 2017), labour market institutions and reforms imposed by the European Commission (Jappelli \& Pistaferri, 2010). Filling the gap therefore 
has always had priority on the Italian political agenda, at least since the WWII. Until the beginning of the $1990 \mathrm{~s}$, in fact, policies to reduce regional inequality had a long-standing application, from favouring employment in public companies in heavy industries to building infrastructures, in the South. Later on, investments turned to become mainly net income maintenance transfers, with cut or substantially reduced capital formation, bringing about a relative income drop in the South (D’Antonio \& Scarlato, 2008, Fabrizi, Ferrante \& Pacei, 2014). Standing such inequality condition, it becomes prominent to identify the negative place-specific consequences of nationwide shocks (Di Caro, 2014), and the effect of fiscal consolidation policies after recessions (Figari \& Fiorio, 2015).

Due to austerity measures in the past ten years, Southern regions saw a large increase in the relative cost of credit. The national government reduced transfers to local governments, which had to downsize public services provision; regional trade and transfers diminished, unemployment increased, mass job losses occurred and weak labour demand depressed real wages. All these mechanisms exacerbated the Italian regional disparity issue.

Other OECD countries such as France, Spain, Germany, the United Kingdom, and the United States have experienced similar increasing trend of income inequality since the beginning of the 1990s (Brandolini \& Smeeding, 2005). Germany had a disparity issue when integrating Eastern with Western regions. However, contrary to the Italian South, East Germany inherited a rich institutional framework, administrative efficiency and more social capability (Boltho, Carlin, \& Scaramozzino, 1997). In this article we provide evidence on the degree of regional resilience of GDP per capita to the last crisis. In fact, one distinctive feature of the Great Recession was the degree of resilience of Italian regions' employment growth after the two shocks. Faggian, Gemmiti, Jaquet, and Santini (2018) show that Southern regions have a lower level of resistance to recessions compared to the Centre and the largest regions of the North (Lombardy, Piedmont, Veneto, Trentino Alto Adige, Emilia 
Romagna). Only Abruzzo, in the South, showed recovery capacity. However, every region displays a significant degree of heterogeneity in growth rates, and the convergence path allowed Southern regions' growth drop to be smaller than the average. Nonetheless, the latter regions keep - each - the most unequal income distribution.

Our data show that "between-region" inequality has not changed/deteriorated after the Great Recession, while "within-region" increased substantially and remained the main source of personal income inequality in Italy. We also provide evidence on within-region 'quantilespecific' increasing inequality from 2007 (peak) to 2012 (through) for each region and macro area, and discuss the role of the crisis in augmenting such inequality.

The literature exploring within-group inequality in Italy is limited. At least to our knowledge, few studies examine the topic, without giving a quantitative size of the correlation of personal income inequality to individual features before and after the crisis. Our paper tries to fill this gap.

Our main research objective therefore is to explore whether personal income inequality, inside regions, has increased during the crisis, and to identify individual/household features correlated to such increase. To this purpose, we conduct a quantile regression analysis of the ln-equivalised income and its time variation, taking specific population features as exogenous variables. Such disaggregated quantitative analysis helps at identifying the weakest categories of individuals/households who should receive attention in designing targeted regional income support policies that are still missing.

The paper proceeds as follows. The next section deals with the existing literature and theoretical background linking a financial/economic crisis to income inequality (and its determinants). The third section sketches some stylized facts on Italian regional heterogeneity. The fourth section describes data, indicators, variables and methodology. The fifth section shows and discusses qualitative evidence on personal income inequality before and during the 
crisis inside regions. The sixth section reports the results of the quantile regression approach, indicating which specific population features are the most sensitive to economic downturns, at least in Italy, needing more policy effort. The seventh section provides concluding remarks.

\section{Literature review and theoretical background}

There are four main mechanisms transforming a financial crisis into a socio-economic one (Ötker-Robe \& Podpiera, 2013). A financial crisis reduces the availability of credit and pushes interest rates up, thus weakening economic activity. It reduces financial flows across regions and causes the erosion of savings. Consequent dampened aggregate demand lower incomes and real wages (McKenzie, 2004), increases job losses, unemployment and vulnerable employment. Baldacci, de Mello \& Inchauste (2002) argue that financial crises are associated with increases in poverty and in some cases in economic inequality. Aggregate volatility and macroeconomic shocks, in fact, are associated to increasing poverty and inequality (Calderòn \& Levy-Yeyati, 2009). Finally, countries with small fiscal room or adopting austerity measures (such as Eurozone after the sovereign-debt crisis) reduce income support such as cash transfers to households and other welfare provisions (Del Pino \& Pavolini, 2015), sharpening economic inequality (Matsaganis \& Leventi, 2014) or even pushing poverty rate higher (Gutiérrez, 2014). These channels worked in Italy as well. Southern regions saw a large increase in the relative cost of credit. Due to austerity, the national government reduced transfers to local governments, which had to downsize public services provision; regional trade and transfers diminished (apart from automatic stabilizers, see Bussolo, Krolage, Makovec, Peichl, Stoeckli \& Torre, 2018), unemployment increased, mass job losses occurred and weak labour demand depressed real wages. These mechanisms increased within-region income inequality.

The literature exploring the determinants of within-group inequality in Italy is limited. Few studies highlight immigrant groups income inequality (authors, 2018), the role of life 
expectancy (De Vogli, Mistry, Gnesotto \& Cornia, 2005), and education (Rodriguez-Pose \& Tselios, 2009). Bogliacino and Maestri (2016) discuss the change of regional inequality in Italy in a wider European context, but they stop in 2008 and show that within-region inequality in macro-regions of Italy decreased from 2007 to 2008, without giving a quantitative size of the correlation of inequality to individual features. Our paper is close to the latter in the spirit and fits this field of empirical research, but with substantial differences.

We analyse the features of personal income inequality within regions before and during the crisis. In order to pick the determinants of income inequality, we follow the suggestion of Checchi and Peragine (2010), who find that gender and geographical area of residence are correlated to inequality of opportunities: women and Southern regions residents suffer from more inequality of economic and social opportunities; Ballarino, Bernardi, Requena, and Schadee (2009) who argue that income and education play an important role for inequality of opportunities: social origin affects education outcome and inequality. In addition, they show that household structure, such as the number of household members and the presence of children, importantly affect household's income: larger households with very young children are penalized. Foreign immigrants for economic reasons might have contributed to change regional income distributions as well (Dell'Aringa, Lucifora, \& Pagani, 2015). Card (2001) and Ottaviano and Peri (2012) document the role of migrations to increase local and nationwide inequality. In Italy, similarly to elsewhere in Europe, migrant workers are largely concentrated in low skilled and low-paid jobs even when highly educated (Strøm, Piazzalunga, Venturini, \& Villosio, 2018). The recession heavily affected those jobs, but the growth of foreign employment, although lower than its pre-crisis values, continued to be positive even when the GDP growth rate turned negative (Figari \& Fiorio, 2015; Venturini \& Villosio, 2018). 
As far as the choice of inequality measures, we follow Cerqueti and Ausloos (2015) and Jenkins (1999) and calculate income inequality with four measures. The Gini index, Palma ratio, one measure of the General Entropy class GE(-1), sensitive to differences at the bottom of the distribution (and to very small incomes, Cowell \& Flachaire, 2007), one measure of the Atkinson class $\mathrm{A}(0.5)$, sensitively capturing differences at the top tail. Both $\operatorname{GE}(-1)$ and $\mathrm{A}(0.5)$ are decomposable to evaluate whether inequality originates from within regions or between regions. The choice of such inequality indexes derives primarily on evidence of strong differences in income shares by population quintiles, both for Italy and for each region, from pre-crisis to crisis year (Jahn, 2016).

On the policy side, the high disparity existing in 2007 within each region (an economic boom year in Italy), and its persistence at the peak of the crisis year, 2012, calls for at least two considerations. First, public measures existed already in the pre-crisis period, to support individual income in Italy for different categories of individuals, such as monetary integration for temporary layoffs in downturns, ${ }^{2}$ subsidies to the unemployed and pre-pension schemes for elderly workers. However, the social protection system was quite fragmented and sometimes discriminatory (Boeri \& Garibaldi, 2008, Fabrizi et al., 2014). Only 20\% unemployed individuals were eligible to receive a subsidy in 2006 (compared to $75 \%$ in France and $80 \%$ in Germany) even if unemployment was at $6.8 \%$ in the country and quite heterogeneous across regions, ranging from $2.9 \%$ in Valle d'Aosta (North) to $13.4 \%$ in Sicily (South). Regional heterogeneity in unemployment is a policy concern because highunemployment regions are those regions with high inequality (Banca d'Italia, 2018). Policies reducing regional unemployment would therefore reduce regional inequality differences. As Anastasia, Mancini and Trivellato (2009) observe Italy devoted 26.4\% of GDP to social protection policies in 2006 but $20 \%$ of the Italian population was still at risk of poverty, worse than the EU15 average. Moreover, before 2007, the Italian legislation did not provide any 
"income of last resort" for people at risk of poverty or long-run unemployment. Furthermore, the actual system of fiscal transfers and benefits performed rather poorly in terms of effectiveness and fairness. Therefore, a debate started on the opportunity to reform the social welfare and tax-transfer regime, proposing, among others, a "guaranteed minimum income" to sustain people in poverty conditions, the poor elderly, disabled individuals and their families, and parents with children (Aaberge, Colombino \& Strøm, 2004).

Second, the two subsequent economic and debt crises in 2008-2009 and 2011-2012 almost stopped the European regional convergence process. However, no specific recommendation was given to Italy to combat social exclusion and poverty (Deffaa, 2016).

After 2007, however, there were two significant institutional reforms at the national level: the National-Regional Government Agreement of 2009-2012, and the Law 92/2012 reforming the labour market and social security system. These important reforms changed drastically the welfare system of income support from mere reimbursement and monetary transfers in crisis periods to a welfare to work regime, where regional employment offices increased their territorial autonomy at helping workers strengthening their capability and human capital formation (ISFOL, 2014). ${ }^{3}$ Nonetheless, we cannot capture yet any significant impact of such measures with our available data, because of their slow and fragmented enforcement.

\section{Stylized facts}

A stylized fact, which holds for a number of EU countries, is that regional disparities increased during the crisis. Italy makes no exception in this regard, as documented in official sources (OECD, 2015; ISTAT, 2017). Many of the OECD countries such as France, Germany, Spain, the United Kingdom, and the United States have experienced similar increasing trend of income inequality. The main concern is that, unlike those countries, Italy's income inequality is slightly above the OECD average in 2013 (Iyke \& Ho, 2017). 
In the last year of growth before the burst of the crisis, 2007, as documented by OECD data, ${ }^{4}$ the average Gross Value Added growth rate (GVA) was positive in Italy, positive in the macro-regions and positive in all administrative regions. In 2009 Italy experienced an average regional drop in GVA growth equal to $-3.42 \%$, and after a weak recovery, in 2012 Italy fell back into heavy recession: all macro regional growth rates were negative, and only three regions experienced a positive GVA growth (with respect to previous year): Valle d'Aosta $(+0.70 \%)$, Trentino Alto Adige $(+1.95 \%)$ and Puglia $(+0.57 \%) .{ }^{5}$ The regions with the worst drop in GVA between 2007 and 2012 were Friuli Venezia Giulia, Liguria and Lazio (reduction of around 7\%).

The second fact is that the Gini index increased in almost all regions with the crisis (as reported in Table 1). However, Southern regions are the most unequal both in 2007 and in 2012. Appendix B corroborates these findings in Figure B1. The correlation between GVA growth rates of the administrative regions and the Gini index is negative and significant (0.38) in 2007. In the expansionary time, regions with high growth are also those with low inequality. On the other hand, the correlation in 2012 turns slightly positive $(+0.03)$. Indeed, those regions whose income is commonly less unequally distributed were also those with a greater drop in value added growth rates. Therefore, when growth is below zero, the relationship flips over, but the inequality 'divide' is still there. Large Southern regions, although showing resilience with a smaller drop in growth rates, are not able to reduce their income inequality. This result is consistent with the evidence about a (new) resilience pattern of Southern regions in the 2000s (Di Caro, 2015, Faggian et al., 2018).

\section{Data, indicators and methodology}

Data are retrieved from the European Union Statistics on Income and Living Conditions (EU-SILC) Survey, for Italy only. The databases EU-SILC 2008 and EU-SILC 2013 report cross-sectional individual (and household) disposable incomes of the previous fiscal year, 
2007 and 2012 respectively, which are our pre-crisis and crisis time of analysis. Appendix A describes the available information from EU-SILC in detail. We calculate four inequality measures, that are the Gini index, Palma ratio, one measure of the General Entropy class GE($1)$, and one measure of the Atkinson class $\mathrm{A}(0.5)$. The choice of such inequality indexes, as explained in Section 2, derives primarily on evidence of strong differences in income shares by population quintiles, both for Italy and for each region. Section 5 discusses in detail the evidence on movements of income inequality before and during the crisis inside regions.

Next, a standard quantile regression analysis ${ }^{6}$ allows identifying what individual and household features are correlated to individual income along the distribution, whether these correlations vary with quantiles, and whether they change from an expansionary time to a recessionary one. The specification for each quantile follows a linear equation:

$$
\text { (1) } Q_{y / X}(x, \tau)_{t}=\alpha(\tau)+X_{t} \beta(\tau)+\gamma(\tau) \cdot G D P_{k t}+\sum_{r=1}^{20} \delta(\tau) \cdot R_{r}+\varepsilon_{t}
$$

Where $Q_{y / X}(x, \tau)$ is the $\tau$-th quantile of the conditional distribution of $y_{t}$ on variables $X=x$. Time $t=2007$ or $2012, k=1, \ldots, 4$ indicates macro-regions, $r=1, \ldots, 20$ single regions, $\mathrm{N}=$ number of individuals. $\quad \beta(\tau)=\frac{\partial Q_{y / X}(x, \tau)}{\partial x}(L \times 1), \quad \gamma(\tau)=\frac{\partial Q_{y / X}(x, \tau)}{\partial G D P} \quad$ and $\quad \delta(\tau)=$ $\frac{\partial Q_{y / X}(x, \tau)}{\partial R}(20 \times 1)$ are vectors of marginal effects (semi-elasticities) of altering the components of $\mathrm{X}$ on the $\tau$-th quantile of the conditional distribution. All parameter vectors are non-specified function of $\tau$, in our assumption. $y_{t}$ is the vector of $\ln$-(equivalised-household) incomes, i.e. per capita income of each household member weighted in proportion to the member's needs (as explained in Appendix A). Matrix $X_{t}(N \times L)$ includes $L$ explanatory variables (corresponding to the determinants exposed in Section 2): dummies for marital status (one if legally married), gender (one if female), nationality (one if migrant), three different stages of education (lower than secondary, secondary and tertiary education), 
individual employment status at the time of the survey (one if employed). It includes also integer variables such as individual age, household size, an interaction between gender and number of (less than 16 years-old) children in the household. The local economic and labour market conditions, which affect income distribution, are approximated by the macro-regional $G D P_{k t}$ growth rate at time $t$ (with respect to year $t-1$ ) and twenty regional dummies $R$. Appendix A extensively describes the construction of all variables and Table B1 in Appendix B reports descriptive statistics.

\section{A qualitative assessment of income inequality inside regions}

Table 1 reports the set of income inequality measures, distinguishing by time and space. They relate to Italy as a whole and separately to each macro-region and the twenty NUTS2 regions. The test of significance of each measure between 2007 and 2012 captures whether inequality changed after the two economic recessions.

Clearly, all indexes significantly increase on average in the South. On the other hand, in the North West and Centre all average indexes but the Palma ratio increase, while in the North East there is no significant difference in any index. If we look at the Palma ratio for total individuals in Italy, the top $10 \%$ income earners have $13.6 \%$ more than double income of bottom $40 \%$ earners. In 2012 , this percentage goes up to $21.9 \%$. The interesting point here is that this proportion differs quite a lot across regions, where we observe a North-South divide. In Sicily, as an example, top $10 \%$ earners receive $35.4 \%$ more than double income of bottom $40 \%$ in 2012. However, only households in Liguria and Sicily had a statistically significant increase in the Palma ratio during the economic crisis.

The last two rows of Table 1 report a general decomposition of $\mathrm{GE}(-1)$ and $\mathrm{A}(0.5)$ into within and between-region inequality. Within-region inequality measured by GE(-1) doubled in 2012, while between-region inequality did not change significantly with the crisis. 
Table 1. Income inequality across Italian regions. [about here]

Notes: Regions are ranked by ascending Gini index in $2007 . * 10 \%, * * 5 \%, * * * 1 \%$ significance levels for the test of significance of each index between 2007 and 2012. Source: Authors' calculations from EU-SILC 2008 and EU-SILC 2013 data.

We extend the qualitative evidence of Table 1 in Appendix B, which shows graphically the income share differences between 2007 and 2012 by population quintiles, at the country, macro-regional and regional level, using the methodology of Jahn (2016). The top panel of Figure B2 shows income share differences for the whole sample. Income in Italy decreased in the first quintile $(0-20 \%$ population share) of the distribution by a significant $-0.53 \%$ whilst it increased in the fifth quintile ( $80-100 \%$ population share) by $0.86 \%$. In the middle part of the distribution (from the second to the fourth quintile), changes were negligible (on average $0.11 \%$ ). Within each macro-region, the crisis affected only the bottom and top quintiles of the income distribution, but not in the North East, where there is no significant difference in average share changes. However, heterogeneity among regions is evident even in the North East. In Veneto, for example, there was a substantial positive change for the fifth quintile, and a negative change for the fourth quintile $(60-80 \%$ share, see Figure B3). Notice that the crisis hit the North East manufacturing sector harshly, forcing more than 7400 small and medium firms to close down in 2012, one third of total Italian closedowns (the sector delivers medium-high personal incomes, given that most manufactures are micro self-employed firms, Unioncamere, 2014).

The highest decrease in the first quintile, however, appears in the South (-1.3\%) and Centre $(-0.4 \%)$, and the highest income increase at the top of the distribution (both around $+1 \%$ ) are there as well. During the crisis, workers at the bottom income distribution suffered from either unemployment (mainly in the South) or temporary layoffs (Centre-North), and they were eligible to monetary integrations. Workers at the top of the distribution, on the other hand, had lower probability to become unemployed, with greater mobility within or across sectors 
(especially in financial and business services). Specialization and export capacity (mainly in Agricultural and Construction activities in the South, Manufactures in the North and Arts and Entertainment activities in the Centre, Eurostat, 2013), companies restructuring and education of workers are important determinants of regional resilience after a negative shock.

Figure B3 provides equivalent evidence for each region. The highest decrease at the bottom of the distribution in Liguria (-1.7\%), Trentino Alto Adige (-1.1\%) in the North, Molise (-1.5\%), Campania (-1.6\%) and Sicily $(-2.2 \%)$ in the South. On the other side, the highest increase at the top are in Liguria $(+3 \%)$ and Sicily $(+2 \%)$. Interestingly, Liguria despite belonging to the highly developed North West suffered heavily from the crisis. One explanation lies on household composition. The average household size in Liguria is lower than the national one ( 2 members compared to 2.4$)$ and there is a relatively high presence of elderly people living alone (ISTAT, 2017). Moreover, regional specialization in affected manufacturing subsectors (Zanin, 2014) helps explaining this finding.

\section{The results of the quantile regression analysis}

Quantile regression analysis is a useful and appropriate method to deal with income inequality. It allows documenting what individual and household features are commonly associated to separate quantiles of the conditional income distribution, and whether this correlation varies from an expansionary time to a recessionary one. Table 2 reports the marginal effects (or semi-elasticities) and standard errors for the quantile regressions: we pick the 20th quantile, the 50th quantile (median income) and top 100\% quantile (top income). For each quantile, results relate to 2007 and 2012. Moreover, in the three columns referring to year 2012 there are also the results of a t-test of equality for each coefficient of the following null hypotheses:

$$
H_{0}: \hat{\beta}_{l, \tau, 2007}=\hat{\beta}_{l, \tau, 2012} \forall l ; \hat{\gamma}_{k, \tau, 2007}=\hat{\gamma}_{k, \tau, 2012} \forall k ; \hat{\delta}_{r, \tau, 2007}=\hat{\delta}_{r, \tau, 2012} \forall r=1, . .20
$$


Where $\hat{\beta}_{l}$ is the estimated semi-elasticity for each variable in the $X$ matrix of eq.(1) for the $\tau$ th quantile, $\hat{\gamma}_{k}$ is the estimated semi-elasticity for macro-region $k$ 's GDP growth rate, and $\hat{\delta}_{r}$ is the estimated semi-elasticity for each regional dummy $r$. The test allows documenting which factors significantly changed their correlation with income with the economic crisis, at different classes of income. Factors are those explored in the literature (section 2) such as gender, household size, whether the individual is a mother, education, migrant status, geographical residence. We add as well the employment status, age, married status, and the macro region development level.

Contrary to other evidence, women and men are not different in the 20th quantile of the income distribution, and this "equality" does not change with the crisis. Although this fact turns out to hold for bottom as well as median income, women with median income significantly lose in 2012, which is in line with the official statistics on poverty and social exclusion (see https://www.istat.it/it/archivio/16777). Indeed, more than 50\% of Italian women are at risk of poverty or social exclusion during the period 2007-2012, and the percentage increased with the Great Recession. When looking at top income earners, women have even an advantage in the expansionary year, but the male-female gap decreases to nil with the crisis.

On the other hand, women in households with young children have always a significant disadvantage (versus men) in all income classes, as expected. The semi-elasticity of the interaction, in fact, is negative and significant everywhere and in the two periods, and women even worsen their position in the lowest quantile in 2012 (t-test favours the alternative $\mathrm{H}_{1}$ : $\hat{\beta}_{l, 0.2,2007}=-0.08>\hat{\beta}_{l, 0.2,2012}=-0.105$ at $1 \%$ level $)$. Notice that the highest female-male gap for this interaction is at the top of the distribution $\left(\hat{\beta}_{l, 0.2,2007}=-0.237\right.$ in 2007 and $\hat{\beta}_{l, 0.2,2012}=-0.161$ in 2012 , significant at $1 \%$ and $10 \%$ levels respectively). These results add new evidence on the existing about, for example, gender pay discrimination (Mussida \& 
Picchio, 2014). It is possible to envisage three possible explanations. The first has to do with how Eurostat defines the equivalised-income, assigning the under-16-years-old a lower weight in the calculation of household income. The second would derive from gender composition, where female could be under-represented in the household. We check for the role of the first (and second) adult in the household, finding that it is equally distributed across genders, around a half of men is first (second) adult in EU-SILC data. Therefore, there are no gender composition effects affecting our calculations. A third potential source for these results are family duties, which qualify as a policy matter. In general, the presence of a female member - interacted with household composition - pushes women to exit the formal labour market, especially in the South (Figari, Paulus, \& Sutherland, 2011, Fabrizi et al., 2014). Reconciling work and family duties still lays on women in Italy, who generally tend to give up to an additional source of income. Family-friendly policies appear more often linked to private companies' agreements and allowances, but during the crisis firms had to suspend such practices (Broughton, 2013, Eurofound, 2015). Our results highlight a weakness of public welfare intervention.

Although household size seems to be associated to higher household income in the expansionary year, its coefficient is negative and significant in the recessionary year, for the bottom and median income earners, so large households become penalized after a crisis. The coefficient is yet positive for the top class.

Possessing secondary education is an advantage at all levels of income - with respect to having a lower than secondary education, as found in the literature - but this advantage is reduced after the crisis for individuals at the median. A double advantage do have individuals with tertiary degrees, double with respect to secondary and lower education, and again there is a slight reduction in the semi-elasticity for median income (t-test favours the alternative $\mathrm{H}_{1}$ : $\hat{\beta}_{l, 0.5,2007}=0.4>\hat{\beta}_{l, 0.5,2012}=0.383$, significant at $10 \%$ level). The investment in tertiary 
education is an insurance against bad economic downturns (OECD, 2013). However, In Italy the percentage of individuals with tertiary education is lower than the OECD average (around $25 \%$ compared to an average $39 \%$ in 2012 ). We observe that education is most valuable to those at the bottom tail and that a North-South divide exists in the percentage of highly educated. These geographical differentials have not declined despite increasing educational attainment levels of the Italian population (ISTAT, 2015), suggesting that there is scope for regional (even provincial) policies.

Migrant individuals have a disadvantage with respect to nationals about their income in all quantiles, as expected. At the bottom and median levels, migrants suffered an even stronger disadvantage in the crisis year (Strøm et al., 2018). However, the highest gap with nationals in terms of income class rests on the top quantile in both years.

Age is positively associated to income in the top quantile in both years, but the correlation becomes negative or zero in the bottom and median quantiles. We notice a disadvantage for young people, especially when labor market reforms started in the late 1990s, with the objective of expanding employment opportunities by introducing new types of temporary contracts. In this regard, young people are frequently employed with temporary contracts offering low wages, hardly escaping a low-income trap (Boeri, 2011). The disadvantage of young people, as well as young household, is confirmed by the latest evidence available from Banca d'Italia (2018).

One's employment status is definitely an advantage in terms of income at all quantiles. The estimated semi-elasticities are positive and significant. However, employed individuals suffered an income loss in the crisis year, at all income classes. As discussed in Section 2, passive measures to support income are national instruments (see note 2) but with differential application according to the regional economic structure. Starting from 2007, the distribution of only one of the integration instruments (CIGs in deroga) falls within the scope of each 
region. Given that the social protection system in Italy is quite fragmented, even the 20092012 welfare system reforms appear to be slow and insufficient to fill the North-South top/bottom income gap in this respect.

Married individuals have always an advantage with respect to any other social status, and it is even more important to be married during the crisis for bottom income earners.

Finally, average macro regional GDP growth favours income at all levels and the two periods, as expected. As far as regional dummies, we interpret the estimated coefficients relative to the regions of reference (Valle d'Aosta and Molise, dropping because of their small economic size and sectorial structure, too similar to their neighbour regions). Regions in the North West provide heterogeneous results. Individuals in Piedmont suffer from a reduced income in all quantiles in 2007 and 2012. Lombardy shows no significant difference over time except for the middle class, that shows positive semi-elasticity in 2012. Liguria shows a significant negative difference, especially at the bottom income levels. Calabria, Campania and Sicily suffer from a lower level of income at all quantiles in 2007, and income drops even more in 2012, especially in the lower and median quantiles. Other regions in the South, such as Abruzzo, Puglia and Sardinia, manage to reduce the income gap in 2012 (see the discussion on resilience in Section 3). The middle class suffers less from the crisis in Lombardy, the Central regions and in Abruzzo, relative to other regions.

Table 2. Quantile regressions of ln-equivalised income [about here]

Notes: Bootstrap-standard errors in parentheses. A constant term is included in all regressions. $* 10 \%, * * 5 \%, * * * 1 \%$ levels. Columns ' $t$ ', the significance level of a coefficient-equality test over the two periods (at the same quantiles) is reported. Source: Authors' elaborations on EU-SILC data.

\section{Conclusions}

This work provides evidence of income inequality change from an expansionary pre-crisis year to a recessionary crisis year, inside regions of Italy. Italy is interesting because its 'structural' regional disparities originate well before the latest financial and economic crisis of 
2008-2009, thus filling the North-South gap has always been on top of the political agenda. Policies to reduce regional inequality have a long-standing application: from industrial investments in the South to income support policies and tax-transfers regimes, and their tentative reforms during the crisis period. Labour market reforms of the 2000s as well, involved all Italian regions, especially the South. The impact of such regulations in Italy is that "between-region" inequality has not changed significantly after the recession, while "within-region" inequality increased substantially and remained the main source of inequality, even after netting out the impact of support policies. We find evidence that the lowest disposable income shares, especially in Southern and Central regions, decreased significantly in 2012, while income shares of the middle class on average seem not significantly affected. Middle class suffered less from the crisis in Lombardy (due to high resilience of its economic structure), in Central regions (due mainly to a lower concentration of migrant households and sectorial specialization), in Abruzzo (which is the only Southern region denoting a relatively high degree of resilience during the crisis). Nonetheless, some categories of individuals in middle/bottom classes suffered particularly during the crisis.

The analysis shows that women and men are not different for bottom as well as median income classes, but women with median income significantly lose with the crisis. Moreover, women in households with young children have always a significant disadvantage (versus men) at all income classes (evidence of gender discrimination). Here is where support policy is lacking. Policy aiming at increasing female employment in the formal labour market and favouring women with children to access or re-enter the labour market should be of public concern. This is particularly true in a crisis period, when Italian private companies usually withdraw or postpone family-friendly working reconciliation policies. Yet, solutions in Italy appear more often linked to firm-level agreements, while public welfare intervention is still lagging behind. A second important result is that migrants have a much higher probability to 
fall into a bad state after a negative shock. Public intervention should focus on specific educational and training programs as well as better job-matching for this category of workers and their families. Third, higher education is most valuable to those at the bottom income class, even if a North-South divide in this dimension should again orienting targeted policies. Finally, income support policy in the period observed was fragmented, slow, and insufficient to protect employment and to fill the North-South top/bottom income gap.

\section{Acknowledgements}

We wish to thank Inmaculada Mohino and José Marìa Ureña and the participants at the NECTAR Cluster 4 Meeting 'Travel, migration, housing and labour market in a context of crisis. Lessons for the future' held in Toledo in October 2016.

\section{References}

Aaberge, R., Colombino, U., \& Strøm, S. (2004). Do More Equal Slices Shrink the Cake? An Empirical Investigation of Tax-Transfer Reform Proposals in Italy. Journal of Population Economics, 17, 767-785.

Anastasia, B., Mancini, M., \& Trivellato, U. (2009). Il sostegno al reddito dei disoccupati: note sullo stato dell'arte. Tra riformismo strisciante, inerzie dell'impianto categoriale e incerti orizzonti di flexicurity. Istituto di Studi e Analisi Economica, ISAE, Working Paper n. 112.

Baldacci, E., de Mello, L., \& Inchauste, G. (2002). Financial Crises, Poverty and Income Distribution. International Monetary Fund WP/02/4. Washington, DC.

Ballarino, G., Bernardi, F., Requena, M., \& Schadee, H. (2009). Persistent inequalities? Expansion of education and class inequality in Italy and Spain. European Sociological Review, 25(1), 123-138. 
Banca d'Italia (2018). Relazione annuale anno 2017 [Annual report 2017]. Divisione Editoria e stampa della Banca d'Italia, Rome, IT.

Boeri, T. (2011). Institutional Reforms and Dualism in European Labor Markets, in O. Ashenfler and D. Card, eds., Handbook of Labor Economics, (Elsevier Science, 2011), 4b, $1173-1236$.

Boeri, T., \& Garibaldi, P. (2008). Un nuovo contratto per tutti [A new contract for all]. Chiarelettere ed., Milano.

Bogliacino, F. \& Maestri, V. (2016). Wealth Inequality and the Great Recession, Intereconomics: Review of European Economic Policy, 51(2), 61-66.

Boltho, A., Carlin, W., \& Scaramozzino, P. (1997). Will East Germany become a new Mezzogiorno? Journal of Comparative Economics, 24, 241-264.

Brandolini, A., \& Smeeding, T.M. (2005). Inequality Patterns in Western Democracies: Cross-Country Differences and Time Changes. Unpublished manuscript.

Broughton, A. (2013). EU employers take family-friendly working seriously. Eurofound. Luxembourg: Publication Office of the European Union. Retrieved from https://www.eurofound.europa.eu/observatories/eurwork/articles/quality-of-life/surveylooks-at-workand-family-life

Bussolo, M., Krolage, C., Makovec, M., Peichl, A., Stoeckli, M., \& Torre, I. (2018). Vertical and Horizontal Redistribution: the Case of Western and Eastern Europe. Paper of the World Bank Regional Report on "Distributional tensions and the sustainability of the social contract in Europe and Central Asia".

Calderon, C., \& Yeyati, E. L. (2009). Zooming in : from aggregate volatility to income distribution, Policy Research Working Paper Series 4895, The World Bank. 
Canale, R.R., \& Napolitano, O. (2015). National disparities and cyclical dynamics in Italy (1892-2007): was the Mezzogiorno a sheltered economy? International Review of Applied Economics, 29(3), 328-348.

Card, D. (2001). Immigrant Inflows, Native Outflows, and the Local Market Impacts of Higher Immigration. Journal of Labor Economics, 19(1), 22-64.

Cerqueti, R., \& Ausloos, M. (2015). Statistical assessment of regional wealth inequalities: the Italian case. Quality and quantity, 49, 2307-2323.

Checchi, D., \& Peragine, V. (2010). Inequality of opportunity in Italy. Journal of Economic Inequality, 8, 429-450.

Cowell, F.A., \& Flachaire, E. (2007). Income distribution and inequality measurement: The problem of extreme values. Journal of Econometrics, 141, 1044-1072.

D’Antonio, M., \& Scarlato, M. (2008). Centre and periphery in development policy for the South. Review of Economic Conditions in Italy, 2, 213-243.

Deffaa W. (2016). The New Generation of Structural and Investment Funds - More Than Financial Transfers? Intereconomics, 51(3),155-163.

De Vogli, R., Mistry, R., Gnesotto, R., \& Cornia, G.A. (2005). Has the relation between income inequality and life expectancy disappeared? Evidence from Italy and top industrialised countries. Journal of Epidemiology \& Community Health, 59, 158-162.

Dell'Aringa, C., Lucifora C., \& Pagani, L. (2015). Earnings differentials between immigrants and natives: the role of occupational attainment. IZA Journal of Migration, 4(8), 1-18.

Del Pino, E., \& Pavolini, E. (2015). Decentralisation at a Time of Harsh Austerity: Multilevel Governance and the Welfare State in Spain and Italy Facing the Crisis. European Journal of Social Security, 17(2), 147-157. 
Di Caro, P. (2014). Shocking Aspects of Mezzogiorno: Resilience, Vulnerability and Regional Growth. Rassegna Economica, 77(2).

Di Caro, P. (2015). Recessions, recoveries and regional resilience: Evidence on Italy. Cambridge Journal of Regions, Economy and Society, 8(2), 273-291.

Eurofound. (2015). Working and caring: Reconciliation measures in times of demographic change. Luxembourg: Publications Office of the European Union.

Eurostat (2013). Eurostat Regional Yearbook. Retrieved from http://ec.europa.eu/eurostat/web/products-statistical-books/-/KS-HA-13-001.

Fabrizi, E., Ferrante, M.R., \& Pacei, S. (2014). A Micro-Econometric Analysis of the Antipoverty Effect of Social Cash Transfers in Italy. Review of Income and Wealth, 60(2), 323-348.

Faggian, A., Gemmiti, R., Jaquet, T., \& Santini, I. (2018). Regional economic resilience: the experience of the Italian local labor systems. Annals of Regional Science, 60, 393-410.

Figari, F., \& Fiorio, C. V. (2015). Fiscal Consolidation Policies in the Context of Italy's Two Recessions. Fiscal Studies, 36, 499-526.

Figari, F., Paulus, A., \& Sutherland, H. (2011). Measuring the size and impact of public cash support for children in cross-national perspective. Social Science Computer Review, 29(1), 85-102.

Gagliardi, L., \& Percoco, M. (2011). Regional Disparities in Italy over the Long Run: the role of Human Capital and Trade Policy. Region et Developpement, 33, 81-105.

Gould, W. (1998). Interquantile and simultaneous-quantile regression. Stata Technical Bulletin, 7, 38, 167-176. 
Gutiérrez, R. (2014). Welfare Performance in Southern Europe: Employment Crisis and Poverty Risk. South European Society and Politics, 19(3), 371-392.

ISFOL (2014). Ammortizzatori sociali in deroga e politiche attive del lavoro: monitoraggio dell'attuazione, degli esiti e degli effetti dell'Accordo Stato-Regioni 2009-2012. Volume 1, Roma, IT.

ISTAT. (2015). Annuario Statistico Italiano, Tav.3.13, 2014 [Italian Statistics Annual]. Roma, IT.

ISTAT. (2016). Stima preliminare del PIL. II Trimestre 2016 [Preliminary estimate of GDP. $2^{\text {nd }}$ quarter 2016]. Roma, IT.

ISTAT. (2017). Disuguaglianze, distribuzione della ricchezza e delle risorse finanziarie. Audizione del Presidente dell'Istituto nazionale di statistica Giorgio Alleva. Roma, IT.

Iyke, B.N., \& Ho, S. (2017). Income Inequality and Growth: New Insights from Italy. Economia Internazionale / International Economics, 70(4), 419-442.

Jahn, B. (2016). Assessing inequality using percentile shares. (University of Bern Social Sciences Working Paper No. 13). Bern, CH: University of Bern. Retrieved from http://ideas.repec.org/p/bss/wpaper/13.html.

Jappelli, T., \& Pistaferri, L. (2010). Does consumption inequality track income inequality in Italy? Review of Economic Dynamics, 13(1), 133-153.

Jenkins, S. P. (1999). Analysis of income distribution. Stata Technical Bulletin, sg104, 4-18. authors (2018).

Matsaganis, M. \& Leventi, C. (2014). The Distributional Impact of Austerity and the Recession in Southern Europe. South European Society and Politics, 19(3), 393-412. 
McKenzie, S. (2004). Social sustainability: towards some definitions: Hawke Research Institute Working Paper Series No. 27, University of South Australia.

Mussida, C. \& Picchio, M. (2014). The gender wage gap by education in Italy. Journal of Economic Inequality, 12(1), 117-147.

OECD (2013). Education at a Glance 2013: OECD Indicators. Paris: OECD Publishing. OECD (2015). In It Together: Why Less Inequality Benefits All. OECD Publishing, Paris.

Otker-Robe, I., \& Podpiera, A. M. (2013). The social impact of financial crises: evidence from the global financial crisis, Policy Research Working Paper Series 4895, The World Bank.

Ottaviano, G. I. P., \& Peri, G. (2012). Rethinking the Effects of Immigration on Wages. Journal of the European Economic Association, 10(1), 152-197.

Rodríguez-Pose, A., \& Tselios, V. (2009). Education and income inequality in the regions of the European Union. Journal of Regional Science, 49 (3), 411-437.

Strøm, S., Piazzalunga, D., Venturini, A., \& Villosio, C. (2018). Wage assimilation of immigrants and internal migrants: the role of linguistic distance. Regional Studies, 52(10), $1423-1434$

Unioncamere. (2014). Movimprese. Retrieved from www.infocamere.it, on October 19, 2016.

Venturini, A. \& Villosio, C. (2018). Are migrants an asset in recession? Insights from Italy. Journal of Ethnic and Migration Studies, 44(14), 2340-2357.

Zanin, L. (2014). On Okun's law in OECD countries: an analysis by age cohorts. Economics Letters, 125, 243-248. 


\section{Notes}

${ }^{1}$ Italy includes twenty administrative regions: Piedmont, Valle d'Aosta, Lombardy, Liguria (North West), Trentino Alto Adige, Veneto, Friuli Venezia Giulia, Emilia Romagna (North East), Tuscany, Marche, Umbria, Lazio (Centre), Abruzzo, Molise, Puglia, Campania, Basilicata, Calabria, Sicily, Sardinia (South).

${ }^{2}$ Cassa integrazione guadagni ordinaria, CIG, straordinaria, CIGs, in deroga, CIGsder, are integration measures to help workers who temporarily lose their job. These and other passive measures are national instruments, differing for sector of activity, firm size, seniority and pay level, type of occupation, whether temporary or permanent, part-time or full-time, household composition and duration of the support.

${ }^{3}$ In the same four years, resources amounted to $€ 2526$ million to Southern regions, $€ 1174$ million to Central regions, $€ 2581$ million to Northern regions, $34.2 \%$ financed through Regional Operative Program to support passive measures of income support. More than 800 thousand workers were eligible and received a 'treatment', $60 \%$ of them were men, mostly coming from micro and small companies with a permanent contract. Unemployed workers received a 'participation reimbursement' only if they were available to participate to new active labour programs. In 2009-2012, only Lombardy, Veneto, Emilia Romagna and Piemonte delivered 50\% of total treatments (ISFOL, 2014).

${ }^{4}$ http://www.oecd-ilibrary.org/economics/data/oecd-national-accounts-statistics_na-data-en.

${ }^{5}$ Italy experienced 12 quarters of negative GDP growth starting from IV2011 ending on III2014, with regional heterogeneity (ISTAT, 2016).

6 Technically, a simultaneous quantile regression with bootstrapped standard errors, with 'between-quantile' blocks variance/covariance matrix of the estimator (Gould, 1998). 